\title{
Efeitos temporais e espaciais no consórcio intercalar de milho e feijão(1)
}

\begin{abstract}
Roger Delmar Flesch ${ }^{(2)}$
Resumo - Épocas de semeadura de milho (Zea mays L.) e arranjos espaciais foram estudados em consórcio intercalar entre milho (cv. Pioneer 6872) e feijão (Phaseolus vulgaris L. cv. Rio Tibagi), em Chapecó, SC, com o objetivo de determinar as combinações agronômica e economicamente mais eficientes dos sistemas consorciados. Cinco experimentos foram conduzidos anualmente e consistiram de cinco épocas de semeadura do milho em relação ao feijão, com quatro arranjos espaciais para cada época de semeadura. $\mathrm{O}$ delineamento experimental foi o de blocos casualizados, com quatro repetições. O milho foi semeado 15 dias antes do feijão, simultaneamente ao feijão e 15, 30 e 45 dias depois do feijão. Os arranjos espaciais foram $1 \mathrm{M}: 1 \mathrm{~F}$ (uma fileira de milho alternada com uma fileira de feijão), $2 \mathrm{M}: 2 \mathrm{~F}$, 2M:3F e 1M:2F. A época de semeadura e o arranjo espacial influenciaram o rendimento de grãos do milho e do feijão. Os arranjos mais eficientes para o milho foram $1 \mathrm{M}: 1 \mathrm{~F}$ e $2 \mathrm{M}: 2 \mathrm{~F}$ e para o feijão foram $1 \mathrm{M}: 2 \mathrm{~F}$ e 2M:3F. A semeadura antecipada de 15 dias do feijão em relação ao milho aumentou em $35 \%$ a produção do feijão enquanto reduziu a do milho em 7,5\%. A eficiência agronômica e econômica dos sistemas consorciados aumentaram com a antecipação da semeadura do feijão.
\end{abstract}

Termos para indexação: Zea mays, Phaseolus vulgaris, arranjo espacial, época de semeadura, rendimento.

\section{Temporal and spatial effects on maize-bean row intercropping}

\begin{abstract}
Maize (Zea mays L.) planting dates and spatial arrangements between maize (cv. Pioneer 6872) and common bean (Phaseolus vulgaris L. cv. Rio Tibagi) in a row intercropping system was conducted in Chapecó, SC, Brazil, to determine the best agronomic combinations and the economically most efficient intercropping system. Five experiments were carried out annually and consisted of five maize planting dates in relation to bean, with four spatial arrangements for each planting date. The experimental design was randomized complete blocks with four replications of each treatment. Maize was planted 15 days before bean, simultaneously to bean, and 15, 30 and 45 days after bean planting. The spatial arrangements were $1 \mathrm{M}: 1 \mathrm{~B}$ (one maize row alternated with one bean row), $2 \mathrm{M}: 2 \mathrm{~B}, 2 \mathrm{M}: 3 \mathrm{~B}$ and $1 \mathrm{M}: 2 \mathrm{~B}$. Planting dates and spatial arrangements influenced the yields of maize and common bean. The most efficient spatial arrangements for maize were $1 \mathrm{M}: 1 \mathrm{~B}$ and $2 \mathrm{M}: 2 \mathrm{~B}$ and for common bean were $1 \mathrm{M}: 2 \mathrm{~B}$ and $2 \mathrm{M}: 3 \mathrm{~B}$. Early planting of common bean by 15 days over maize increased its yield by $35 \%$ while the maize yield was reduced by $7.5 \%$. Agronomic and economic efficiency of row intercropping over sole cropping increased with common bean early planting.
\end{abstract}

Index terms: Zea mays, Phaseolus vulgaris, spatial arrangement, sowing date, yields.

\section{Introdução}

A consorciação de culturas foi usada nas pequenas propriedades do Sul do País, nas décadas de 60 e 70 e início dos anos 80 , sendo o consórcio do feijão com milho o mais comum. Em Santa Catarina, essa

(1) Aceito para publicação em 30 de março de 2001.

(2) Empresa de Pesquisa Agropecuária e Difusão de Tecnologia de Santa Catarina, Caixa Postal 791, CEP 89801-970

Chapecó, SC. E-mail: rogerdf@epagri.rct-sc.br prática sempre foi adotada por proprietários de pequenas áreas e poucos recursos, em áreas de relevo acidentado, com predominância da associação de milho e feijão, principalmente na região Oeste do Estado. Flesch \& Espíndola (1985) estimaram que cerca de 160.000 ha ( $40 \%$ da área) de feijão foram cultivados em associação com milho naquele ano. Atualmente, a área de cultivo consorciado de milho e feijão em Santa Catarina é estimada em cerca de 30.000 ha, e, basicamente, em consórcio de substituição do milho pelo feijão. 
Diferentes arranjos espaciais foram utilizados pelos agricultores catarinenses na consorciação de feijão com milho. Os mais comuns na década de 70 consistiam de duas fileiras de milho alternadas com duas ou três fileiras de feijão, e semeadura de milho a cada duas ou três fileiras de feijão por ocasião da maturação fisiológica deste (Vieira et al., 1980). Os mesmos autores observaram que os arranjos em faixas alternadas estavam substituindo os arranjos tradicionais em virtude da maior vantagem econômica e facilidade com os tratos culturais. Por outro lado, Kranz \& Gerage (1982), no Paraná, testaram 13 arranjos espaciais entre milho e feijão, e constataram que $1 \mathrm{M}: 2 \mathrm{~F}$ e $1 \mathrm{M}: 3 \mathrm{~F}$ apresentavam maior rendimento econômico que os demais, provavelmente, pela maior população do feijão e maior preço comparado ao milho. Vieira (1985) reconhece como melhores arranjos os utilizados pelos agricultores, dada a sua menor complexidade e maior praticidade na condução da lavoura.

Num cultivo consorciado, as espécies normalmente diferem em altura e em distribuição das folhas no espaço, entre outras características morfológicas, que podem levar as plantas a competir por energia luminosa, água e nutrientes. A divisão da radiação solar incidente sobre as plantas, em um sistema consorciado, será determinada pela altura das plantas e pela eficiência de intercepção e absorção. O sombreamento causado pela cultura mais alta reduz tanto a quantidade de radiação solar à cultura mais baixa como a sua área foliar (Trenbath, 1976). Uma vez que a radiação solar afeta o desenvolvimento da segunda cultura semeada, a escolha do melhor arranjo e da época ideal de semeadura é crucial no desempenho da consorciação, ou seja, na maximização da produção. No oeste de Santa Catarina, região de exploração intensiva da avicultura e suinocultura, era muito comum a semeadura antecipada do milho sobre o feijão, para garantir a produção de milho à alimentação animal. Assim, o milho, com porte superior ao feijão, sempre garantiu uma boa produção em detrimento do feijão, que produzia menos da metade de uma lavoura solteira. Faria (1980) sugere que a semeadura do feijoeiro seja feita 25 a 10 dias antes do milho, para uma boa complementação entre os dois cultivos, tendo em vista os diferentes ciclos de cultivo e a utilização de nutrientes, água e radiação solar por essas duas culturas. Willey (1979b) relata que a semeadura anterior de uma cultura sobre a outra torna-a mais competitiva, e uma semeadura posterior torna-a menos competitiva, comparada à semeadura simultânea. Francis et al.(1976) constataram, na Colômbia, que o rendimento do feijão caiu para menos da metade quando o milho foi semeado de 5 a 15 dias antes. Por outro lado, quando o feijão foi semeado antes do milho, a produção do feijão aumentou e alcançou $75 \%$ da obtida no cultivo solteiro.

O objetivo deste trabalho foi avaliar os efeitos de arranjos e épocas de semeadura de feijão e milho em cultivo consorciado na eficiência agronômica e econômica do sistema consorciado.

\section{Material e Métodos}

Experimentos de campo foram realizados em 1983/84, 1984/85 e 1986/87 em um Latossolo Roxo distrófico (Erexim), no Município de Chapecó, SC. Anualmente foram realizados cinco experimentos, que consistiram de cinco épocas de semeadura de milho em relação ao feijão, em quatro arranjos espaciais entre milho e feijão. $\mathrm{O}$ delineamento experimental utilizado em cada época foi o de blocos casualizados, com quatro repetições. A partir da data de semeadura do feijão (época 2), foram estabelecidas as datas de semeadura do milho, com intervalos de 15 dias entre si: época 1 (E1): milho semeado 15 dias antes do feijão em 30/8 nos anos agrícolas 1983/84 e 1984/85, e em 28/8 no ano 1986/87; época 2 (E2): milho e feijão em semeadura simultânea nos dias 14/9, 13/9 e 12/9 nos anos 1983/84, 1984/85 e 1986/87, respectivamente; época 3 (E3): milho semeado 15 dias após o feijão em 29/9 nos anos 1983/84 e 1984/85, e em 26/9 no ano 1986/87; época 4 (E4): milho semeado 30 dias após o feijão, no dia 13/10 nos anos agrícolas 1983/84, 1984/85 e 1986/87; época 5 (E5): milho semeado 45 dias após o feijão, em 28/10, 29/10 e 27/10 nos anos 1983/84, 1984/85 e 1986/87, respectivamente.

Os arranjos espaciais utilizados para o milho e feijão foram: $1 \mathrm{M}: 1 \mathrm{~F}$ (uma fileira de milho alternada com uma fileira de feijão), 1M:2F, 2M:2F e 2M:3F. Em cada época cultivos solteiros de milho e feijão foram conduzidos em parcelas adicionais. A largura das parcelas variou de acordo com o arranjo utilizado, porém o comprimento foi sempre de 6,60 m. No arranjo 1M:1F, a distância entre fileiras de milho foi de $1,0 \mathrm{~m}$, com uma fileira intercalada de feijão a 0,50 m do milho. No arranjo $1 \mathrm{M}: 2 \mathrm{~F}$, a distância entre fileiras de milho foi de $1,50 \mathrm{~m}$, com duas fileiras de feijão 
intercaladas e distanciadas $0,50 \mathrm{~m}$ entre si. Nos arranjos 2M:2F e 2M:3F, a distância entre as fileiras de milho foi de $0,50 \mathrm{~m}$. As fileiras intercalares de feijão distanciaram-se de $0,50 \mathrm{~m}$ entre si e entre as fileiras pareadas de milho. Nos arranjos $1 \mathrm{M}: 1 \mathrm{~F}$ e $2 \mathrm{M}: 2 \mathrm{~F}$ foram utilizadas 50.000 plantas/ha de milho e 100.000 plantas/ha de feijão; no arranjo $2 \mathrm{M}: 3 \mathrm{~F}$ foram utilizadas 40.000 plantas/ha de milho e 120.000 plantas/ha de feijão, e no arranjo $1 \mathrm{M}: 2 \mathrm{~F}$ foram utilizadas 33.333 plantas/ha de milho e 133.333 plantas/ha de feijão. As áreas úteis das parcelas dos arranjos $1 \mathrm{M}: 1 \mathrm{~F}, 2 \mathrm{M}: 2 \mathrm{~F}, 2 \mathrm{M}: 3 \mathrm{~F}$ e $1 \mathrm{M}: 2 \mathrm{~F}$ foram de $12 \mathrm{~m}^{2}, 12 \mathrm{~m}^{2}, 15 \mathrm{~m}^{2}$ e $9 \mathrm{~m}^{2}$, respectivamente.

Como reagentes foram utilizadas as cultivares Rio Tibagi, feijão preto com hábito de crescimento indeterminado tipo II, e o milho híbrido Pioneer 6872, de ciclo precoce, nos três anos de experimentos. A adubação da área foi feita anualmente com aplicação de 4,5 t/ha de esterco seco de aves. $\mathrm{O}$ esterco foi aplicado a lanço e incorporado com grade, uma semana antes da semeadura da E1.

Em decorrência da estiagem ocorrida em dezembro de 1983, o milho da E2 foi prejudicado e teve os dados considerados perdidos, razão pela qual foram utilizadas apenas as médias dos outros dois anos para esta época de semeadura.

Foram avaliados os seguintes parâmetros: a) rendimento de grãos: após a colheita e trilha do milho e do feijão, foi feita a determinação da umidade e obtido o peso dos grãos, cujos valores foram padronizados para $13 \%$ de umidade e extrapolados para $\mathrm{kg} / \mathrm{ha}$; b) índice de equivalência de área (IEA): foi calculado conforme Willey (1979a), e é definido como a área relativa de terra, em cultivo solteiro, necessária para ter os mesmos rendimentos que o cultivo consorciado. O seu cálculo é feito pela seguinte fórmula: $\mathrm{IEA}=\mathrm{MC} / \mathrm{MS}+\mathrm{FC} / \mathrm{FS}$, onde MC e FC são os rendimentos de grãos do milho e feijão consorciados, e MS e FS são os rendimentos do milho e feijão em cultivo solteiro. Para a época $\mathrm{E} 2$, foram considerados apenas os rendimentos do milho e do feijão dos dois últimos anos; c) renda bruta: foi determinada pela multiplicação do rendimento de grãos do milho e do feijão consorciados pelos seus respectivos preços mínimos, para cada arranjo dentro das épocas. Em relação à época $\mathrm{E} 2$, foram considerados apenas os rendimentos do milho e do feijão dos dois últimos anos. Os preços mínimos utilizados foram os vigentes para a safra 1999/2000: feijão, R \$28,00/saco ou R \$ 0,467/kg, e milho R\$ 7,10/saco ou R\$ 0,118/kg.

Os resultados foram submetidos à análise da variância obedecendo ao modelo em blocos ao acaso, e as médias comparadas pelo teste de Duncan a 5\% de probabilidade.

\section{Resultados e Discussão}

O rendimento de grãos de milho consorciado, nos quatro arranjos, variou significativamente dentro de cada época de semeadura (Tabela 1). Em E1, o rendimento do milho no arranjo $1 \mathrm{M}: 1 \mathrm{~F}$ foi maior que no arranjo 2M:2F, e o contrário ocorreu em E5. Nas demais épocas de semeadura, esses dois arranjos não diferiram significativamente entre si, porém foram superiores aos dois outros arranjos. Os arranjos 1M:1F e 2M:2F mantiveram a mesma população do milho em cultivo solteiro (50.000 plantas/ha) e possuíram 10.000 e 16.667 plantas a mais do que os arranjos $2 \mathrm{M}: 3 \mathrm{~F}$ e $1 \mathrm{M}: 2 \mathrm{~F}$, respectivamente. $\mathrm{O}$ resultado acima confirma as afirmações de Fukai \& Trenbath (1993) e Vieira (1999), de que para a obtenção de um alto rendimento de grãos num sistema consorciado, a principal cultura deve manter uma alta densidade populacional.

O rendimento do milho consorciado diminuiu a partir de E1, com a maior redução a partir de E3, em todos os arranjos (Tabela 1). De E1 até E3, a redução média da produtividade do milho entre os arranjos foi de 7,5\%, enquanto de E1 até E5 a redução média foi de $34 \%$. Tais resultados confirmam a afirmação de Francis (1978) de que o milho semeado antes ou

Tabela 1. Rendimento (kg/ha) de grãos de milho e de feijão, em cultivo solteiro e consorciado, em diferentes arranjos, por época de semeadura. Média de três anos agrícolas. Chapecó, $\mathrm{SC}^{(1)}$.

\begin{tabular}{|c|c|c|c|c|c|}
\hline \multirow{2}{*}{$\begin{array}{l}\text { Época de } \\
\text { semeadura } \\
\text { do milho }^{(2)}\end{array}$} & \multicolumn{4}{|c|}{ Arranjo $^{(3)}$} & \multirow{2}{*}{$\begin{array}{l}\text { Cultivo } \\
\text { solteiro }\end{array}$} \\
\hline & $1 \mathrm{M}: 1 \mathrm{~F}$ & $2 \mathrm{M}: 2 \mathrm{~F}$ & $2 \mathrm{M}: 3 \mathrm{~F}$ & $1 \mathrm{M}: 2 \mathrm{~F}$ & \\
\hline & & & Milho & & \\
\hline E1 & $6.468 \mathrm{a}$ & $5.919 b$ & $5.242 \mathrm{c}$ & $4.879 \mathrm{c}$ & 6.880 \\
\hline E2 & $5.846 \mathrm{a}$ & $5.328 \mathrm{ab}$ & $4.645 \mathrm{c}$ & $4.796 b c$ & 6.564 \\
\hline E3 & $5.834 \mathrm{a}$ & $5.630 \mathrm{a}$ & $4.964 b$ & $4.477 \mathrm{c}$ & 6.730 \\
\hline E4 & $4.872 \mathrm{a}$ & $4.737 \mathrm{a}$ & $4.453 \mathrm{ab}$ & $4.038 \mathrm{~b}$ & 5.908 \\
\hline \multirow[t]{2}{*}{ E5 } & $3.808 \mathrm{~b}$ & $4.257 \mathrm{a}$ & $3.503 \mathrm{~b}$ & $3.257 \mathrm{c}$ & 4.644 \\
\hline & & & Feijão & & \multirow{6}{*}{2.007} \\
\hline E1 & $590 \mathrm{~b}$ & $636 b$ & $982 \mathrm{a}$ & $1.015 \mathrm{a}$ & \\
\hline E2 & $727 b$ & $786 b$ & $1.025 \mathrm{a}$ & $1.116 \mathrm{a}$ & \\
\hline E3 & $891 \mathrm{c}$ & $919 \mathrm{c}$ & $1.190 \mathrm{~b}$ & $1.292 \mathrm{a}$ & \\
\hline E4 & $1.274 \mathrm{c}$ & $1.249 \mathrm{c}$ & $1.414 \mathrm{~b}$ & $1.560 \mathrm{a}$ & \\
\hline E5 & $1.708 \mathrm{~b}$ & $1.487 \mathrm{c}$ & $1.610 \mathrm{~b}$ & $1.939 \mathrm{a}$ & \\
\hline
\end{tabular}

${ }^{(1)}$ Médias na linha seguidas pela mesma letra não diferem entre si, pelo teste de Duncan, a 5\% de probabilidade. ${ }^{(2)}$ E1: 15 dias antes do feijão; E2: simultânea ao feijão; E3: 15 dias depois do feijão; E4: 30 dias depois do feijão; E5: 45 dias depois do feijão. ${ }^{(3)}$ Arranjos dispostos em fileiras de milho (M) alternadas com fileiras de feijão (F). 
simultaneamente com o feijão é pouco afetado em seu rendimento. Como no presente trabalho, Kranz et al. (1982), no Paraná, também observaram redução na produção do milho quando ele foi semeado em pré-floração do feijão. O rendimento de grãos de milho solteiro foi semelhante nas três primeiras épocas e diminuiu cerca de $1.000 \mathrm{~kg} /$ ha para cada época de semeadura seguinte. Esses resultados sugerem que o feijão exerceu pouca competição sobre as plantas de milho nas três primeiras épocas, mas aumentou a partir de $\mathrm{E} 4$. O rendimento do milho em E4 e E5 também foi afetado negativamente pela época de semeadura, fato confirmado pela redução ocorrida no rendimento do cultivo solteiro naquelas épocas. Esses resultados diferem dos relatados por Francis et al. (1982b), que observaram grandes reduções na produtividade do milho semeado 10 dias após o feijão, possivelmente pelas condições climáticas da região onde o experimento foi realizado, sugerindo que naquela região o milho deve ser semeado simultaneamente ao feijão para manter a produtividade do cultivo solteiro.

O rendimento de grãos de feijão consorciado diferiu estatisticamente entre os arranjos em cada época de semeadura e aumentou à medida que o milho foi semeado mais tarde em relação ao feijão (Tabela 1). O arranjo 1M:2F foi superior em rendimento aos demais arranjos em E3, E4 e E5. Em E1 e E2, juntamente com 2M:3F, superou os outros dois arranjos. León et al. (1985), na República Dominicana, também observaram que os mais baixos rendimentos do milho foram obtidos nos tratamentos $1 \mathrm{M}: 1 \mathrm{~F}$ e $2 \mathrm{M}: 2 \mathrm{~F}$, onde as plantas estavam mais próximas do milho. A maior produtividade do arranjo $1 \mathrm{M}: 2 \mathrm{~F}$ foi, provavelmente, decorrente da maior população de plantas de feijão, $33 \%, 33 \%$ e $10 \%$ maior do que os arranjos $1 \mathrm{M}: 1 \mathrm{~F}, 2 \mathrm{M}: 2 \mathrm{~F}$ e $2 \mathrm{M}: 3 \mathrm{~F}$, respectivamente. Além disso, a população de milho em 1M:2F foi menor do que nos demais arranjos, confirmando as observações de Vieira (1999) de que quanto menor a população do milho, menor será seu rendimento e maior o do feijão. Em E5, o arranjo 1M:2F teve produtividade quase igual à do cultivo solteiro, demonstrando pouca competição do milho sobre o feijão nessa época.

O pequeno aumento na produtividade do feijão consorciado, nas três primeiras épocas de semeadu- ra, demonstra a competição exercida pelo milho sobre o feijão. De E1 até E3, a produtividade média dos arranjos aumentou apenas $35 \%$, enquanto de E1 até E5 o aumento foi de $119 \%$. Quando as diferenças temporais entre duas culturas são reduzidas, as vantagens de rendimento para as culturas diminuem dada a reduzida complementaridade temporal entre elas (Willey, 1979b). As diferenças em porte e arquitetura, entre as plantas dessas duas espécies consorciadas, favorecem o milho na competição por radiação solar quando elas são semeadas muito próximas (E1 até E3). Além disso, o milho, por causa do sistema radicular mais vigoroso, é favorecido em relação ao feijoeiro na absorção de água e nutrientes (Ofori \& Stern, 1987).

Uma vez que o milho diminuiu a produtividade em cerca de 7,5\% de E1 até E3, e o feijão aumentou-a em $35 \%$, tem-se que a semeadura mais cedo do feijão tornou-o mais competitivo. Assim sendo, sugere-se orientar a semeadura antecipada do feijão sobre o milho em cultivo consorciado em pelo menos 15 dias. Esse período permitirá à planta de feijão se estabelecer e se desenvolver, antes que ocorra a competição do milho, e apresentar produtividade razoável, corroborando as sugestões de Faria (1980). Tal vantagem temporal às plantas de feijão também é sugerida por Sangoi \& Almeida (1993) e Vieira (1999). No entanto, atrasando-se a semeadura do milho em mais de 15 dias em relação à do feijão, o rendimento deste vai aumentar, enquanto o do milho poderá sofrer reduções expressivas.

De maneira geral, o feijão enfrentou maior competição interespecífica do milho nas primeiras épocas de semeadura, e tirou proveito nos arranjos com maior população de plantas e com espaçamentos maiores entre fileiras de milho (2M:3F e $1 \mathrm{M}: 2 \mathrm{~F})$. Nas últimas épocas de semeadura do milho, a competição interespecífica foi menos importante, havendo vantagens para os arranjos com maior população de plantas (1M:2F e $2 \mathrm{M}: 3 \mathrm{~F})$ e com espaçamento maior entre as fileiras de feijão (1M:1F).

A eficiência biológica dos sistemas consorciados sobre os respectivos cultivos solteiros foi medida pelo índice de equivalência de área (IEA), que variou de 1,18 a 1,67, porém não diferiu estatisticamente entre os arranjos em cada época de semeadura (Tabela 2). $\mathrm{Na}$ semeadura antecipada do milho ao feijão, os IEA 
médios foram os mais baixos, mas à medida que a semeadura do milho foi atrasada em relação ao feijão, esse índice foi aumentando até alcançar 1,66 em E5, demonstrando uma superioridade média de até $66 \%$ dos sistemas consorciados sobre os cultivos solteiros. A superioridade dos sistemas consorciados, estimada pelo IEA, também foi observada por Vieira et al.(1980), Francis et al. (1982a), Sangoi \& Almeida (1993) e Raposo et al. (1995), demonstrando ser a consorciação dessas duas culturas uma excelente alternativa para os pequenos produtores.

Outra maneira de avaliar a eficiência dos sistemas consorciados aos respectivos cultivos solteiros é por meio da renda bruta auferida pelos mesmos. A receita bruta do cultivo consorciado foi sempre superior à dos cultivos solteiros (Tabela 3), concordando com os resultados de Vieira et al. (1980). Cabe

Tabela 2. Índice de equivalência de área (IEA) ${ }^{(1)}$ de quatro arranjos de cultivo consorciado entre milho e feijão, em cinco épocas de semeadura. Chapecó, SC.

\begin{tabular}{cccccc}
\hline \multirow{2}{*}{$\begin{array}{c}\text { Época de } \\
\text { semeadura } \\
\text { do milho }\end{array}$} & \multicolumn{4}{c}{ Arranjo $^{(3)}$} & Média \\
\cline { 2 - 4 } & $1 \mathrm{M}: 1 \mathrm{~F}$ & $2 \mathrm{M}: 2 \mathrm{~F}$ & $2 \mathrm{M}: 3 \mathrm{~F}$ & $1 \mathrm{M}: 2 \mathrm{~F}$ & \\
\hline E1 & 1,23 & 1,18 & 1,25 & 1,22 & 1,22 \\
E2 & 1,30 & 1,25 & 1,29 & 1,36 & 1,30 \\
E3 & 1,31 & 1,30 & 1,33 & 1,30 & 1,31 \\
E4 & 1,45 & 1,42 & 1,45 & 1,46 & 1,45 \\
E5 & 1,67 & 1,66 & 1,55 & 1,67 & 1,66 \\
\hline
\end{tabular}

(1) IEA = MC/MS+FC/FS; MC e FC: milho e feijão consorciados ( $\mathrm{kg} / \mathrm{ha}$ de grãos); MS e FS: milho e feijão solteiro (kg/ha de grãos). ${ }^{(2)}$ E1: 15 dias antes do feijão; E2: simultânea ao feijão; E3: 15 dias depois do feijão; E4: 30 dias depois do feijão; E5: 45 dias depois do feijão. ${ }^{(3)}$ Arranjos dispostos em fileiras de milho (M) alternadas com fileiras de feijão (F).

Tabela 3. Receita bruta (R\$) dos sistemas avaliados considerando os preços mínimos do milho e feijão para a safra $1999 / 2000^{(1)}$.

\begin{tabular}{cccccc}
\hline \multirow{2}{*}{$\begin{array}{l}\text { Época de } \\
\text { semeadura } \\
\text { do milho }\end{array}$} & \multicolumn{3}{c}{ Arranjo $^{(3)}$} & & \multirow{2}{*}{$\begin{array}{c}\text { Milho } \\
\text { solteiro }\end{array}$} \\
\cline { 2 - 5 } & $1 \mathrm{M}: 1 \mathrm{~F}$ & $2 \mathrm{M}: 2 \mathrm{~F}$ & $2 \mathrm{M}: 3 \mathrm{~F}$ & $1 \mathrm{M}: 2 \mathrm{~F}$ & \\
\hline E1 & $1.039 \mathrm{ab}$ & $996 \mathrm{~b}$ & $1.077 \mathrm{a}$ & $1.050 \mathrm{ab}$ & 812 \\
E2 & $1.051 \mathrm{a}$ & $1.028 \mathrm{a}$ & $1.076 \mathrm{a}$ & $1.118 \mathrm{a}$ & 775 \\
E3 & $1.104 \mathrm{a}$ & $1.093 \mathrm{a}$ & $1.142 \mathrm{a}$ & $1.132 \mathrm{a}$ & 794 \\
E4 & $1.170 \mathrm{a}$ & $1.142 \mathrm{a}$ & $1.185 \mathrm{a}$ & $1.205 \mathrm{a}$ & 697 \\
E5 & $1.247 \mathrm{ab}$ & $1.197 \mathrm{bc}$ & $1.165 \mathrm{c}$ & $1.290 \mathrm{a}$ & 548 \\
\hline
\end{tabular}

(1)Médias na linha seguidas pela mesma letra não diferem entre si, pelo teste de Duncan, a 5\% de probabilidade; receita bruta do feijão solteiro: $\mathrm{R} \$$ 937,00; preço mínimo do feijão: $\mathrm{R} \$ 28,00=\mathrm{R} \$ 0,467 / \mathrm{kg}$; preço mínimo do milho: $\mathrm{R} \$ 7,10=\mathrm{R} \$ 0,118 / \mathrm{kg} .{ }^{(2)} \mathrm{E} 1: 15$ dias antes do feijão; E2: simultânea ao feijão; E3: 15 dias depois do feijão; E4: 30 dias depois do feijão; E5: 45 dias depois do feijão.(3) Arranjos dispostos em fileiras de milho (M) alternadas com fileiras de feijão (F). destacar que o milho solteiro teve uma produtividade decrescente de E1 a E5 (Tabela 1), que resultou numa rentabilidade inferior a $50 \%$ àquelas dos sistemas consorciados em E5 (Tabela 3). O feijão solteiro também teve rentabilidade inferior, porém aproximada à dos cultivos consorciados em E1 e E2, épocas em que o feijão consorciado enfrentou grande competição do milho. Dentro de cada época, houve variação da receita bruta entre os arranjos apenas em E1 e E5, justamente nas épocas de semeadura em que a competição exercida por uma ou outra cultura foi maior (milho em E1 e feijão em E5). Em E1, a maior produtividade do feijão nos arranjos $2 \mathrm{M}: 3 \mathrm{~F}$ e $1 \mathrm{M}: 2 \mathrm{~F}$ foi a responsável pela maior receita, enquanto nos arranjos $1 \mathrm{M}: 1 \mathrm{~F}$ e $2 \mathrm{M}: 2 \mathrm{~F}$, a maior produtividade do milho foi determinante para aumentar a receita. Em E5, a maior produtividade do feijão e a alta relação de preços entre feijão e milho $(3,9: 1,0)$ foram responsáveis para que o arranjo $1 \mathrm{M}: 2 \mathrm{~F}$ fosse mais rentável que os arranjos 2M:2F e 2M:3F. Estes dois arranjos produziram mais milho e menos feijão do que aquele, porém essa relação foi inferior à dos preços mínimos utilizados no cálculo da receita.

Quanto à rentabilidade bruta em cada época de semeadura, E1 foi menos rentável que as demais épocas. A rentabilidade aumentou sempre de E1 até E5, confirmando a observação anterior de que a antecipação da semeadura do feijão melhora o seu desempenho agronômico e, conseqüentemente, o econômico. Para manter a rentabilidade do sistema, o produtor deve atentar que ao trocar um arranjo espacial por outro, a redução na produtividade de uma cultura deve ser acompanhada de um aumento na produtividade da outra cultura, no mínimo proporcional à relação de preços entre as culturas. Segundo Francis (1978), o retorno econômico é o mais importante critério de decisão para o agricultor na hora da semeadura. O preço do produto na época da semeadura é um bom indicativo da escolha do arranjo e época relativa de semeadura das culturas consorciadas para poder beneficiar aquela de melhor preço.

\section{Conclusões}

1. A variação espacial e temporal entre milho e feijão consorciados influencia o rendimento de grãos dessas culturas.

Pesq. agropec. bras., Brasília, v. 37, n. 1, p. 51-56, jan. 2002 
2. Os arranjos mais eficientes para a produção de milho e de feijão são aqueles que têm maior população tanto de plantas de milho como de feijão.

3. A semeadura do feijão 15 dias antes do milho propicia maior produtividade ao feijão sem afetar a do milho.

4. Os cultivos consorciados propiciam mais vantagens agronômicas e econômicas do que os cultivos solteiros.

\section{Referências}

FARIA, R. T. de. Cultivos associados de milho e feijoeiro. In: IAPAR (Londrina, PR). Cultura do feijão no Estado do Paraná. Londrina, 1980. p. 27-31. (Circular, 18).

FLESCH, R. D.; ESPÍNDOLA, E. A. Cultivares de feijão para consorciação com milho em Santa Catarina. Florianópolis: Empasc, 1985.10 p. (Comunicado Técnico, 92).

FRANCIS, C. A. Multiple cropping potentials of bean and maize. HortScience, Alexandria, v. 13, n. 1, p. 12-17, Feb. 1978.

FRANCIS, C. A.; FLOR, C. A.; TEMPLE, S. R. Adapting varieties for intercropped systems in the tropics. In: PAPENDICK, R. I.; SANCHEZ, P. A.; TRIPLETT, G. B. (Ed.). Multiple cropping. Madison: American Society of Agronomy, 1976. p. 235-253. (Special Publication, 27).

FRANCIS, C. A.; PRAGER, M.; TEJADA, G. Density interactions in intercropping: II. Maize (Zea mays L.) and bush beans (Phaseolus vulgaris L.). Field Crops Research, Amsterdam, v. 5, p. 253-264, 1982a.

FRANCIS, C. A.; PRAGER, M.; TEJADA, G. Effects of relative planting dates in bean (Phaseolus vulgaris L.) and maize (Zea mays L.) intercropping patterns. Field Crops Research, Amsterdam, v. 5, p. 45-54, 1982b.

FUKAI, S.; TRENBATH, B. R. Processes determining intercrop productivity and yields of component crops. Field Crops Research, Amsterdam, v. 34, p. 239-245, 1993.

KRANZ, W. M.; GERAGE, A. C. População e número de plantas de milho por cova em consórcio com feijão. In: REUNIÃO NACIONAL DE PESQUISA DE FEIJÃO, 1., 1982, Goiânia, Anais... Goiânia: Embrapa-CNPAF, 1982. p. 121.

Pesq. agropec. bras., Brasília, v. 37, n. 1, p. 51-56, jan. 2002
KRANZ, W. M.; GERAGE, A. C.; GOMES, J. Época de semeadura do milho em relação aos estágios de desenvolvimento do feijão das águas em sistema de consórcio. In: REUNIÃO NACIONAL DE PESQUISA DE FEIJÃO, 1., 1982, Goiânia, Anais... Goiânia: Embrapa-CNPAF, 1982. p. 116-118.

LEÓN, I. A. B. de; ARBAJE, A. N.; PUEllO, O. B. Rendimiento del fríjol (Phaseolus vulgaris L.) asociado con maíz (Zea mays L.) bajo diferentes arreglos espaciales y cronológicos en San Juan de la Maguana, Republica Dominicana. Investigación, v. 9, n. 1, p. 13-28, 1985.

OFORI, F.; STERN, W. R. Relative sowing time and density of component crops in a maize/cowpea intercrop system. Experimental Agriculture, Cambridge, Inglaterra, v. 23, p. 41-52, 1987.

RAPOSO, J. A. de A.; SCHUCH, L. O. B.; ASSIS, F. N. de; MACHADO, A. A. Consórcio de milho e feijão em diferentes arranjos e populações de plantas, em Pelotas, RS. Pesquisa Agropecuária Brasileira, Brasília, v. 30, n. 5, p. 639-647, maio 1995.

SANGOI, L.; ALMEIDA, M. L. de. Influência do arranjo de plantas e da época de semeadura sobre características agronômicas de milho e feijoeiro consorciados. Pesquisa Agropecuária Brasileira, Brasília, v. 28, n. 10, p. 11731181, out. 1993.

TRENBATH, B. R. Plant interactions in mixed crop communities. In: PAPENDICK, R. I.; SANCHEZ, P. A.; TRIPLETT, G. B. (Ed.). Multiple cropping. Madison: American Society of Agronomy, 1976. p. 129-169. (Special Publication, 27).

VIEIRA, C. Estudo monográfico do consórcio milhofeijão no Brasil. Viçosa, MG: UFV, 1999. 183 p.

VIEIRA, C. O feijão em cultivos consorciados. Viçosa, MG: UFV, 1985. 134 p.

VIEIRA, S. A.; BEN, J. R.; GASTAL, F. L. da C. Avaliação do cultivo de milho e feijão nos sistemas exclusivo e consorciado. Pesquisa Agropecuária Brasileira, Brasília, v. 15, n. 1, p. 19-26, jan. 1980.

WILLEY, R. W. Intercropping: its importance and research needs: Part 1. Competition and yield advantages. Field Crop Abstracts, Amsterdam, v. 32, n. 1, p. 1-10, 1979a.

WILLEY, R. W. Intercropping: its importance and research needs: Part 2. Agronomy and research approaches. Field Crop Abstracts, Amsterdam, v. 32, n. 2, p. 73-85, 1979 b. 